\title{
Waterbirds catch and release a poisonous fish at a mudflat in southeastern Australia
}

\author{
Ivan Sazima ${ }^{1,2}$ \\ 1 Museu de Zoologia, Universidade Estadual de Campinas, Campinas, SP, Brazil. \\ 2 Corresponding author: isazima@gmail.com
}

Received on 26 March 2019. Accepted on 13 May 2019.

\begin{abstract}
Several waterbird species prey on fishes, and usually use only one sensory mode to detect this prey: herons hunt visually guided, whereas ibises mostly search tactilely guided. I report herein events in which a heron and an ibis caught and released a poisonous fish at a mudflat in southeastern Australia. A Great Egret (Ardea alba) that targeted small gerreid fishes caught and immediately released the very toxic pufferfish Tetractenos hamiltoni, with bill washing and discomfort movements afterwards. Two Australian White Ibises (Threskiornis molucca) that probed for bottom-dwelling fishes and crabs caught and handled these pufferfishes for about $60 \mathrm{~s}$, before releasing them. Next, the birds dipped the bill in the water and resumed hunting. Pufferfishes are rarely preyed on by birds, but an Australian bird that feeds on this fish type is the Silver Gull (Chroicocephalus novaehollandiae), which eats the pufferfish Torquigener pleurogramma when it is nontoxic or less harmful.
\end{abstract}

KEY-WORDS: Ardea alba, fishing, prey handling, Tetractenos hamiltoni, Threskiornis molucca.

Several waterbird species habitually prey on fishes, and mostly use only one sensory mode to detect this prey type. For instance, herons and cormorants hunt their prey guided visually, whereas ibises and spoonbills usually search for their prey guided tactilely (Kushlan 1976 \& 1977, Recher et al. 1983, Swennen \& Yu 2004 \& 2008, White et al. 2007, Heath et al. 2009, Murray \& Shaw 2009). Fish species hunted by herons and ibises vary greatly, but pufferfishes are an uncommon prey of fisheating birds (Wodzinsky \& Moreland 1966, Recher \& Recher 1968), likely due to powerful toxins secreted by most pufferfish species and their ability to inflate the body (Whitley 1953, Burklew \& Morton 1971, Wainwright \& Turingan 1997, Isbister et al. 2002, Oliveira et al. 2003). I report herein three episodes of a very poisonous pufferfish caught and released by a heron and an ibis species at a mudflat (tide-influenced marsh) in southeastern Australia.

I observed the three catch and release events at the mudflat $\left(33^{\circ} 50^{\prime} 18^{\prime \prime} S ; 151^{\circ} 04^{\prime} 47^{\prime \prime} \mathrm{E} ; 2 \mathrm{~m}\right.$ a.s.l.) of the Waterbird Refuge wetlands at the Sydney Olympic Park in the urban area of Sydney, New South Wales, southeastern Australia. At the observation site the mudflat is connected to the Parramatta River estuary and is influenced by the tidal regime of the river. Besides the heron and the ibis, other diurnal fish-eating waterbird species (three herons, three cormorants, one spoonbill, and one gull) used the site or closely adjacent areas to forage. As hunting episodes generally are fortuitous and brief, the three events were opportunistically observed with bare eye or through a 70-300 $\mathrm{mm}$ telephoto lens mounted on a SLR camera from a distance of about 3-8 $\mathrm{m}$. Throughout the observational sessions, I used the ad libitum and sequence samplings (Altmann 1974), which are adequate to record fortuitous or rare events. Voucher digital photographs are on file at the Museu de Zoologia da Universidade Estadual de Campinas (ZUEC).

On 11 January 2019 at mid-morning, I observed a Great Egret (Ardea alba) precisely and successfully striking at juvenile gerreid fishes called Common Silverbiddy (Gerres subfasciatus) in the receding tide, when it caught and immediately released a poisonous pufferfish locally named Common Toadfish (Tetractenos hamiltoni). Afterwards, the heron washed the bill twice (Fig. 1A) and displayed repeated signs of discomfort: it opened and closed the bill, and shook the head. After about 2-3 min, the egret resumed hunting at the same place. The pufferfishes are very common at the study site, where they move and forage solitarily or in groups of up to about 20-30 individuals and often approach or join the Silverbiddy groups (Fig. 1B).

On 08 February 2019 at late morning, I observed an Australian White Ibis (Threskiornis molucca) walking slowly, probing in the then murky water and preying on bottom-dwelling fishes and crabs, when it caught a Common Toadfish (Fig. 2A). The bird handled the 

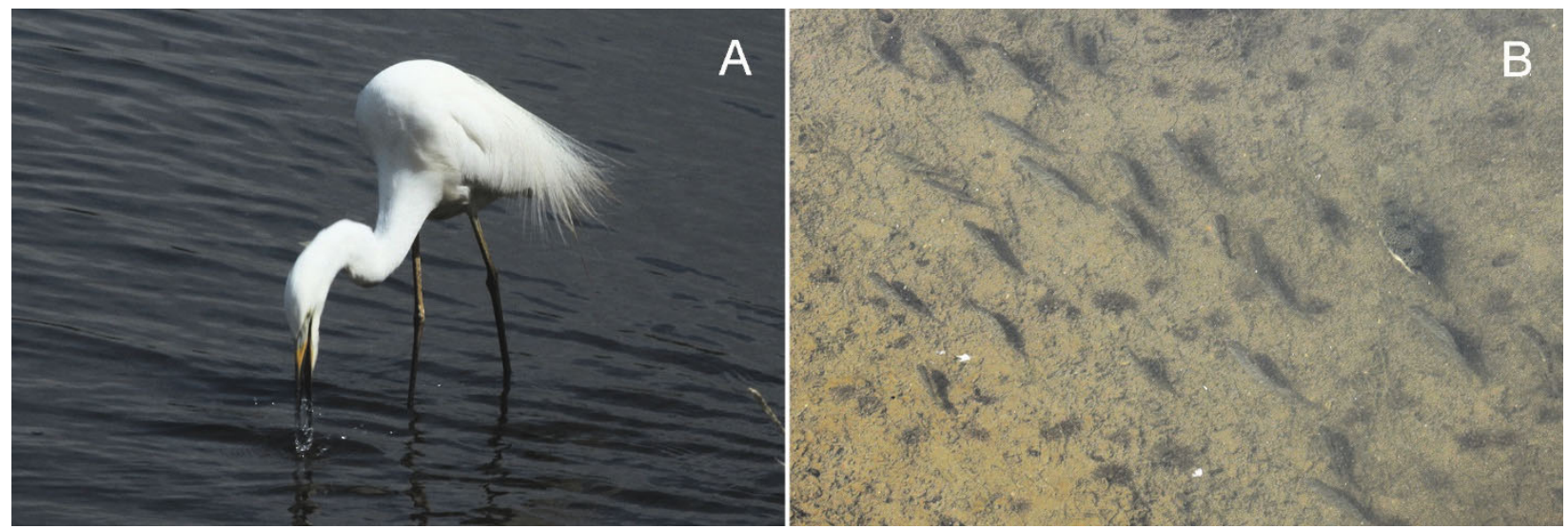

Figure 1. While targeting juvenile Common Silverbiddy (Gerres subfasciatus) as prey, a Great Egret (Ardea alba) washes bill after it caught and immediately released a pufferfish (Tetractenos hamiltoni) in the receding tidal current (A). A group of juvenile Common Silverbiddy moves against the receding tide, the pufferfish T. hamiltoni (outermost spotted fish at right) joining the group (B).

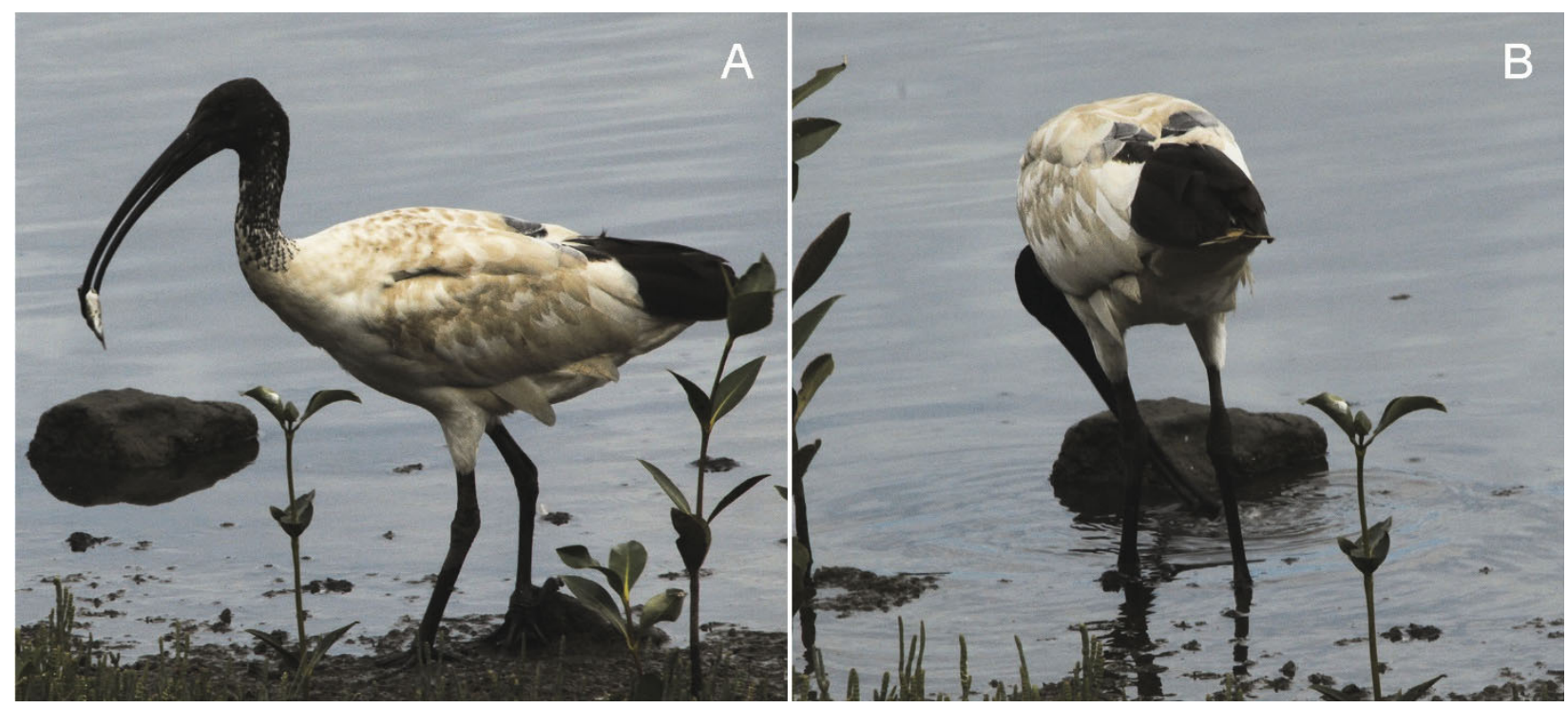

Figure 2. An Australian White Ibis (Threskiornis molucca) holds a pufferfish (Tetractenos hamiltoni) it caught while probing in muddy water (A). The ibis releases the pufferfish after handling it for about $60 \mathrm{~s}$ (B).

pufferfish for about $60 \mathrm{~s}$, and from time to time it made 2-3 lateral movements with its bill in the water before releasing the fish (Fig. 2B). After the pufferfish release, the bird dipped the bill in the water once and resumed hunting. On 18 November 2018 near midday I observed another ibis that caught and released a toadfish, but I had no the same advantageous view as in the description above. However, I noticed that after catching the pufferfish the ibis handled it for about $60 \mathrm{~s}$ and appeared to "cleanse" the fish thoroughly with lateral movements of the bill in the water. After this handling the bird released the pufferfish, dipped the bill in the water and resumed hunting.

The three episodes reported herein indicate that the pufferfish $T$. hamiltoni is an unsuitable and potentially dangerous prey for at least a heron and an ibis species at the studied wetlands, and I think that this assumption may be extended to other heron species, the spoonbill, and the gull as well. The observed Great Egret individual hunted the Common Silverbiddy juveniles with precise visually-oriented strikes, and it likely caught the pufferfish by mistake: an individual of the latter could have intercepted the heron's strikes at the targeted prey, as the two fish species sometimes mingle (present study). The immediate release of the pufferfish and the ensuing bill washing plus the discomfort movements of the egret may be related to the fact that several chemical compounds are aversive to birds and the avoidance reaction occurs at the first contact (Clark et al. 2014). On the other hand, the observed ibises were hunting with tactileoriented shallow probing (sensu Kushlan 1977) in murky water and they caught the pufferfishes possibly without 
recognizing them immediately as an unpalatable and potentially dangerous prey. A possible explanation for the birds handling the fishes for a while before releasing them would be that the ibis is less sensitive than the heron to the pufferfish poisonous secretion, or that its gustatory sense is less developed than that of the heron (Birkhead 2013, Clark et al. 2014), but this remains speculative and needs testing. However, the mere bill dipping in the water before the ibises resumed hunting may lend some support to this suggestion.

Fish-eating birds rarely prey on pufferfishes and when they do, the prey is either small, mildly toxic or nontoxic, or taken sporadically or in very small numbers (e.g., Wodzinski \& Moreland 1966, Recher \& Recher 1968, Hensley \& Hensley 1995, McGrouther 2019). Additionally, toxicity varies between pufferfish genera (Oliveira et al. 2003) and some species within the same genus, e.g., Sphoeroides, may vary from extremely toxic to completely nontoxic (Burklew \& Morton 1971).

An Australian fish-eating bird that forages on a pufferfish species is the Silver Gull (Chroicocephalus novaehollandiae) that eats the Weeping Toadfish (Torquigener pleurogramma) when it is nontoxic or less harmful, as this fish seems to be hazardous only when its gonads are enlarged (McGrouther 2019). An additional or alternative explanation would be that the Silver Gull possibly tolerate toxins (or toxin levels) that could be unpalatable or dangerous to other bird species. However, I have observed that T. hamiltoni discarded by fishermen on jetties near the study site were not eaten by any Silver Gull from groups of 5-20 individuals that lingered there waiting for a morsel such as fish offal or a discarded catch. A few birds inspected the pufferfishes, pecked at them or pinched them once and lost interest on this potential food afterwards. These observations lend support to my assumption that $T$. hamiltoni is hazardous for fish-eating birds in general. The toxin of this pufferfish have caused severe illness and even human deaths (Whitley 1953, Isbister et al. 2002), and it seems reasonable to assume that it would kill birds as well.

\section{ACKNOWLEDGEMENTS}

I thank Marlies Sazima and Ricardo Sazima for support in the field; R. Sazima, Cristina Sazima, and Márcia Bianchi dos Santos for all the help during our stay in Sydney; Dione Serripieri for obtaining hard-to-find literature.

\section{REFERENCES}

Altmann J. 1974. Observational study of behavior: sampling methods. Behaviour 49: 227-267.

Birkhead T. 2013. Bird senses. London: Bloomsbury Publishing.

Burklew M.A. \& Morton R.A. 1971. The toxicity of the Florida Gulf puffers, genus Sphoeroides. Toxicon 9: 205-210.

Clark L., Hagelin J. \& Werner S.J. 2014. The chemical senses in birds. In: Scanes C.G. (ed.). Sturkie's avian physiology. London: Academic Press.

Heath J.A., Frederick P.C., Kushlan J.A. \& Bildstein K.L. 2009. White Ibis (Eudocimus albus). In: Poole A. (ed.). The birds of North America online. Ithaca: Cornell Laboratory of Ornithology. https://doi.org/10.2173/bna.9. (Access on 14 February 2019).

Hensley V.I. \& Hensley D.A. 1995. Fishes eaten by Sooty Terns and Brown Noodies in the Dry Tortugas, Florida. Bulletin of Marine Science 56: 813-821.

Isbister G.K., Son J., Wang F., Maclean C.J., Lin C.S.Y., Ujma J., Balit C.R., Smith B., Milder D.G. \& Kiernan M. 2002. Puffer fish poisoning: a potentially life-threatening condition. Medical Journal of Australia 177: 650-653.

Kushlan J.A. 1976. Feeding behaviour of North American herons. Auk 93: 86-94.

Kushlan J.A. 1977. Foraging behavior of the White Ibis. Wilson Bulletin 89: 342-345

McGrouther M. 2019. Weeping Toadfish, Torquigener pleurogramma (Regan, 1903). https://australianmuseum.net.au/learn/animals/ fishes/weeping-toadfish-torquigener-pleurogramma. (Access on 12 February 2019).

Murray N.J. \& Shaw P.P. 2009. Foraging behaviour and success of Australian White Ibis (Threskiornis molucca) in an urban environment. Notornis 56: 201-205.

Oliveira J.S., Pires-Jr. O.R., Morales R.A.V., Bloch-Jr. C., Schwartz C.A. \& Freitas J.C. 2003. Toxicity of puffer fish - two species (Lagocephalus laevigatus, linaeus [sic] 1766 and Sphoeroides spengleri, Bloch 1785) from the southeastern Brazilian coast. Journal of Venomous Animals and Toxins including Tropical Diseases 9: $1-10$.

Recher H.F., Holmes R.T., Davis-Jr. W.E. \& Morton S. 1983. Foraging behavior of Australian herons. Colonial Waterbirds 6: 1-10.

Recher H.F. \& Recher J.A. 1968. Comments on the escape of prey from avian predators. Ecology 49: 560-562.

Swennen C. \& Yu Y. 2004. Notes on feeding structures of the Blackfaced Spoonbill Platalea minor. Ornithological Science 3: 119-124.

Swennen C. \& Yu Y. 2008. Bill sweeping in spoonbills Platalea: no evidence for an effective suction force at the tip. Journal of Avian Biology 39: 3-6.

Wainwright P.C. \& Turingan R.G. 1997. Evolution of pufferfish inflation behavior. Evolution 52: 506-518.

White C.R., Day N., Butler P.J. \& Martin G.R. 2007. Vision and foraging in cormorants: more like herons than hawks? PLoS ONE 2: e639.

Whitley G.P. 1953. Toadfish poisoning. Australian Museum Magazine 21: 60-65.

Wodzinski K. \& Moreland J. 1966. A note on the food of New Zealand gannets. Notornis 13: 98-99.

Associate Editor: Cristiano S. Azevedo. 